\title{
SISTEM PENDUKUNG KEPUTUSAN MENENTUKAN KELAYAKAN PENERIMAAN BANTUAN PENGUSAHA AYAM PETELUR OLEH DINAS PETERNAKAN KABUPATEN PESAWARAN MENGGUNAKAN METODE SIMPLE ADDITIVE WEIGHTING
}

\author{
Muhamad Muslihudin \\ muslihudinstmikpsw@gmail.com
}

\begin{abstract}
Abstrak
Sistem pendukung keputusan menentukan kelayakan penerimaan bantuan pengusaha ayam petelur oleh dinas kabupaten pesawaran yang belum ada dan di apalikasikan menggunakan computer sehingga dapat mempermudah dan mempercepat dalam pengambilan keputusan. Dalam pengambilan keputusan banyak permasalahan yang harus di putuskan dengan melihat beberapa kriteria (multicriteria) yaitu dalam menentukan penerimaan bantuan yang tepat untuk di jadikan modal usaha peternakan pada kabupaten pesawaran.Konsep dasar metode Simple Additive Weighting (SAW) adalah mencari penjumlahan terbobot dari rating kinerja pada setiap alternative pada semua attribute. Metode Simple Additive Weighting (SAW di pilih karena metode ini menentukan nilai bobot untuk setiap attribute, kemudian di lanjutkan dengan proses perankingan yang akan menyeleksi alternative terbaik dari sejumlah alternative, dalam hal ini alternative yang dimaksud adalah kelayakan penerimaan bantuan pengusaha ayam petelur oleh dinas peternakan kabupaten pesawaran berdasarkan kriteria kriteria yang di tentukan dengan hasil akhir dari perhitungan atau perangkingan diperoleh : $\mathrm{V} 1=64,5, \mathrm{~V} 2=60, \mathrm{~V} 3=58,5, \mathrm{~V} 4=51,5, \mathrm{~V} 5=69,5, \mathrm{~V} 6=61, \mathrm{~V} 7=46$, dan $\mathrm{V} 8=58.5$. Nilai terkecil ada pada perengkingan V7, dengan demikian alternative $A 7$ (budi) adalah alternative yang terpilih sebagai alternative terbaik Oleh karena itu peternakan budi adalah peternakan yang berhak menerima bantuan modal usaha dari dinas kabupaten pesawaran agar bantuan yang diberikan tersebut tepat sasaran.
\end{abstract}

Kata Kunci : Metode Saw, Bobot Nilai, peternakan ayam, Kabupaten Pesawaran.

\section{ABSTRACT}

Design decision support systems help employers determine eligibility for receipt of laying hens by district offices Pesawaran that does not exist and in apalikasikan use the computer so as to facilitate and accelerate decision-making. In making decisions on the many problems that must be decided by looking at some criteria (multicriteria) that in determining the acceptance of appropriate assistance to be made in the farm in the district capital base pesawaran.Konsep Simple Additive weighting method $(S A W)$ is looking for a weighted sum of the performance rating each alternative on every attribute. Methods Simple Additive Weighting (SAW was chosen because this method determines the weight values for each attribute, then proceed with the ranking process that will be the best alternative from a number of alternative, in this case the alternative in question is the feasibility of receiving assistance businessman laying hens by livestock services district Pesawaran based criteria criteria determined by the final result of the calculation and the ranking obtained:V1 $=64,5, V 2=60, V 3=58,5, V 4=51,5$, $V 5=69,5, V 6=61, V 7=46$, and $V 8=58.5$. smallest value is in perangkingan $V 7$, thus alternative A7 (bob) is an alternative that was chosen as the best alternative is therefore breeding cultivation is a ranch entitled to receive capital support from district offices Pesawaran order to aid in the given target.

Keywords: Methods Saw, Weight Value, chicken farm, Pesawaran District.

\section{PENDAHULUAN}

Teknologi Informasi semakin pesat berkembang waktu demi waktu mampu merubah dunia usaha, terutama dalam bisnis, ataupun pemasaran. Memanfaatkan teknologi informasi menjadi hal yang bijak untuk penunjang dalam pengambilan keputusan dalam dunia usaha demi meningkatkan omset, menambah penghasilan dan memberikan nilai ekonomis tentunya. Pada dasarnya pengambilan keputusan adalah suatu pendekatan sistematis suatu masalah dengan pengumpulan fakta, penentuan yang matang dari alternative yang dihadapi, dan pengambilan tindakan yang menurut perhitungan merupakan tindakan yang paling tepat. Dengan adanya 
teknologi infomasi kita dapat menciptakan sistem yang lugas, cepat, nyaman, aman menarik, terpercaya dan memilik jangkuan yang luas.

Dalam penelitian Septiana (2013) dengan kesimpulan sistem pendukung keputusan ini memerlukan fakta-fakta yang dapat dijadikan basis pengetahuan yang terdiri dari telur, ukuran, saran perawatan, jenis telur, dan topografi. Basis aturan dibentuk untuk mengelola basis pengetahuan antara lain aturan fungsi yang menghubungkan telur dengan ukuran, aturan saran yang menghubungkan telur dengan saran, dan aturan ukuran yang menghubungkan telur dengan jenis telur dan topografi. Berdasarkan percobaan yang dilakukan form konsultasi yaitu pengujian hasil konsultasi yang diharapkan, dengan model representasi pengetahuan kaidah produksi menggunakan metode SAW, sistem dapat menentukan kualitas telur dengan benar.

Dalam penelitian Rina Wati, Evi Mayasari (2015) dengan kesimpulan penentuan tingkat kualitas jenis sapi unggul dengan cara mempertimbangkan aspek-aspek terpenting dalam pemilihan kualitas sapi unggul, selain itu penerapan metode SAW (Simple Additive Weighting) pada sistem pendukung keputusan dalam menentukan kualitas sapi unggul dapat dilakukan dengan cara menentukan kriteria yang akan dijadikan acuan dalam pengambilan keputusan. [3]

Kabupaten Pesawaran adalah salah satu daerah yang sedang berkembang di Provinsi Lampung, pada tanggal 17 juli 2007 DPR RI menyetujui pembentukan kabupaten pesawaran yang di bentuk berdasarkan Undang- undang Nomor 33 Tahun 2007 tanggal 10 Agustus 2007 tentang pembentukan kabupaten pesawaran di provinsi Lampung dengan 7 (tujuh) wilayah kecamatan yaitu : Kecamatan gedong tataan, Kecamatan Nergi Katon, Kecamatan Tegineneng, Kecamatan Waylima, Kecamatan Padang cermin, Kecamatan Punduh Pidada, Kecamatan Kedondong. Letak perkantoran komplek kabupaten pesawaran yang sedang berkembang wilayah nya terletak pada kecamatan gedong tataan desa sukajaya pesawaran. Pada saat ini tahap perkembangan pada kantor kantor dinas yang di bangun pada komplek pesawaran sangat cepat dan termasuk dalam perubahan yang pesat diantaranya telah berdiri kantor kantor dinas seperti dinas Pekerja Umum, kantor dinas Pertanian dan perikanan, Dinas Kebudayaan, Dinas Catatan sipil, Dinas Pendidikan, Dinas kesehatan, Badan Pertanahan Nasional, Kementrian Agama[4].

Dinas Pertanian dan Peternakan Kabupaten Pesawaran merupakan salah satu dinas yang bekerja untuk meningkatkan swasembada pangan untuk seluruh wilayah Kabupaten Pesawaran untuk meningkatkan kesejahteraan masyarakat. Peternakan ayam merupakan salah satu penyumbang pangan. Pemerintah Kabupaten Pesawaran, terutama Dinas Pertanian dan Peternakan berperan penting dalam kesejahteraan dan kelangsungan usaha peternak ayam, yaitu salah satu nya dalam bantuan usaha.

Dengan banyaknya usaha peternakan ayam tentu menyulitkan pihak Dinas Pertanian dan Peternakan Kabupaten Pesawaran untuk memberikan bantuan kepada para pengusaha peternakan ayam di seluruh Kabupaten Pesawaran, untuk itu dibuatlah sistem pendukung keputusan yang dapat membantu pihak Dinas Pertanian dan Peternakan Kabupaten Pesawaran agar bantuan yang diberikan dapat tepat sasaran.

Berdasarkan latar belakang di atas dapat dirumuskan permasalahan yang akan diselesaikan yaitu bagaimana merancang sebuah sistem pendukung keputusan dengan menggunakan metode Simple Additive Weighting (SAW) untuk menentukan kelayakan penerima bantuan pengusaha ayam petelur oleh dinas peternakan kabupaten pesawaran.

Tujuan dari penelitian ini adalah untuk merancang, mengaplikasikan serta mengembangkan system pendukung keputusan (SPK) yang mampu memberikan keputusan kelayakan penerima bantuan darai Dinas Peternakan Kabupaten Paswaran metode yang digunakan dalam sistem pendukung 
keputusan adalah metode SAW(Simple Additive Weighting).

\section{METODE}

Metode Simple additive Weighting (SAW) sering juga dikenal istilah metode penjumlahan terbobot. Konsep dasar metode SAW adalah mencari penjumlahan terbobot dari rating kinerja pada setiap alternatif pada semua atribut. Metode SAW membutuhkan proses normalisasi matriks keputusan $(X)$ ke suatu skala yang dapat diperbandingkan dengan semua rating alternative yang ada.

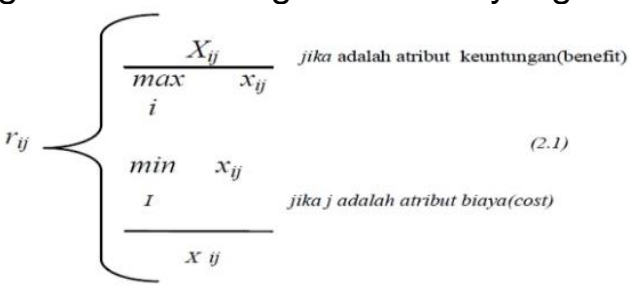

dimana rij adalah rating kinerjaternormalisas $\mathrm{i}$ dari alternatif $\mathrm{Ai}$ pada atribut $\mathrm{Cj} ; \quad \mathrm{i}=1,2, \ldots, \mathrm{m}$ dan $j=1,2, \ldots$, n.Nilai preferensi untuk setiap alternative (Vi)diberikan sebagai:

$$
\mathrm{V} i=\sum_{j=1}^{n} w_{j} r_{i j}
$$

Nilai Vi yang lebih besar mengindikasikan bahwa alternatif Ai lebih terpilih[9].

\section{Kriteria Pembobotan}

Dalam metode penelitian ini ada bobot dan kriteria yang dibutuhkan untuk menentukan penerimaan modal. Adapun kriterianya adalah:

Tabel 1. Kreteria

\begin{tabular}{|c|l|c|}
\hline Kriteria & Keterangan & Nilai \\
\hline C1 & $\begin{array}{l}\text { Luas } \\
\text { Peternakan }\end{array}$ & 10 \\
\hline C2 & Modal Usaha Awal & 20 \\
\hline C3 & Alur Pakan & 10 \\
\hline C4 & Ukuran Kandang & 15 \\
\hline C5 & Jumlah Pegawai & 10 \\
\hline C6 & Jenis Usaha & 15 \\
\hline C7 & $\begin{array}{l}\text { Skala Usaha } \\
\text { Peternakan }\end{array}$ & 10 \\
\hline C8 & Lokasi Peternakan & 10 \\
\hline & & 100 \\
\hline
\end{tabular}

Dari masing-masing bobot tersebut, maka dibuat suatu variable-variabelnya. Dimana dari suatu variable tersebut akan diubah kedalam bilangan fuzzynya. Di bawah ini adalah bilangan fuzzy dari bobot.

1. Sangat Rendah $(S R)=0$

2. Rendah $(R)=0,2$

3. Sedang $(S)=0,4$

4. Tengah $(\mathrm{T} 1)=0,6$

5. Tinggi ( ST $)=0,8$

6. Banyak $(B)=1$

Untuk mendapat variabel tersebut harus dibuat dalam sebuah grafik supaya lebih jelas pada gambar 1 .

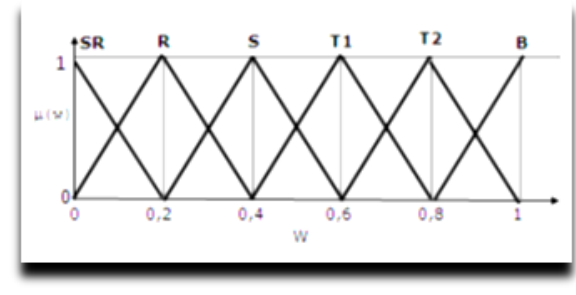

Gambar 1. Grafik bobot

\section{HASIL DAN PEMBAHASAN}

Proses perangkingan dilakukan dengan menggunakan vector bobot masingmasing kriteria yang telah ditetapkan oleh pengambilan keputusan. Vektor bobotnya adalah sebagai berikut :

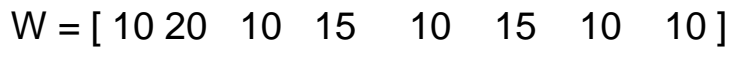

Selanjutnya akan dibuat perkalian matrik $W$ * $R$ dan penjumlahan hasil perkalian untuk memperoleh alternative terbaik dengan melakukan perangkingan nilai terbesar sebagai berikut :

$$
\begin{aligned}
\mathrm{V} 1= & (0,25)(10)+(0.8)(20)+(0.4)(10)+ \\
& (1)(15)+(0.6)(10)+(0.8)(15)+ \\
& (0.4)(10)+(0,5)(10) \\
= & 2,5+16+4+15+6+12+4+5 \\
= & 64,5 \\
\mathrm{~V} 2= & (0,5)(10)+(0.2)(20)+(0.8)(10)+ \\
& (1)(15)+(1)(10)+(0.4)(15)+ \\
& (0.2)(10)+(1)(10) \\
= & 5+4+8+15+10+6+2+10 \\
= & 60 \\
\mathrm{~V} 3= & (1)(10)+(1)(20)+(0.2)(10)+ \\
& (0,4)(15)+(0.2)(10)+(0.2)(15)+ \\
& (0.8)(10)+(0,75)(10)
\end{aligned}
$$




$$
\begin{aligned}
& =10+20+2+6+2+3+8+7,5 \\
& =58,5 \\
V 4= & (0,5)(10)+(0,6)(20)+(1)(10)+ \\
& (0,2)(15)+(0.8)(10)+(0.6)(15)+ \\
& (0.2)(10)+(0,25)(10) \\
= & 5+12+10+3+8+9+2+2,5 \\
= & 51,5
\end{aligned}
$$

$$
\begin{aligned}
\mathrm{V} 5= & (0,75)(10)+(0,4)(20)+(0.8)(10)+ \\
& (0,6)(15)+(0.6)(10)+(1)(15)+ \\
& (0.6)(10)+(1)(10) \\
& =7,5+8+8+9+6+15+6+10 \\
& =69,5
\end{aligned}
$$

$$
\begin{aligned}
& V 6=(1)(10)+(0,2)(20)+(0.6)(10)+ \\
&(0,8)(15)+(1)(10)+(0.4)(15)+ \\
&(0.8)(10)+(0,5)(10) \\
&=10+4+6+12+10+6+8+5 \\
&=61
\end{aligned}
$$$$
\mathrm{V} 7=(0,25)(10)+(0,4)(20)+(1)(10)+
$$$$
(0,2)(15)+(0.8)(10)+(0.2)(15)+
$$$$
(0.4)(10)+(0,75)(10)
$$$$
=2,5+8+10+3+8+3+4+7,5
$$$$
=46
$$

$$
\begin{aligned}
& V 8=(1)(10)+(0,6)(20)+(0.4)(10)+ \\
&(0,6)(15)+(0.2)(10)+(0.6)(15)+ \\
&(1)(10)+(0,25)(10) \\
&= 10+12+4+9+2+9+10+2,5 \\
&= 58,5
\end{aligned}
$$

Hasil perangkingan diperoleh $: \mathrm{V} 1$ (subrenggi) $=64,5, \mathrm{~V} 2=60, \mathrm{~V} 3=$ $58,5, \mathrm{~V} 4=51,5, \mathrm{~V} 5=69,5, \mathrm{~V} 6=61, \mathrm{~V} 7$ $=46$, dan $\mathrm{V} 8=58.5$. Nilai terkecil ada pada perengkingan $\mathrm{V} 7$, dengan demikian alternative $\mathrm{A} 7$ (budi) adalah alternative yang terpilih sebagai alternative terbaik. Oleh karena itu peternakan budi adalah peternakan yang tepat untuk menerima bantuan modal usaha dari dinas kabupaten pesawaran.

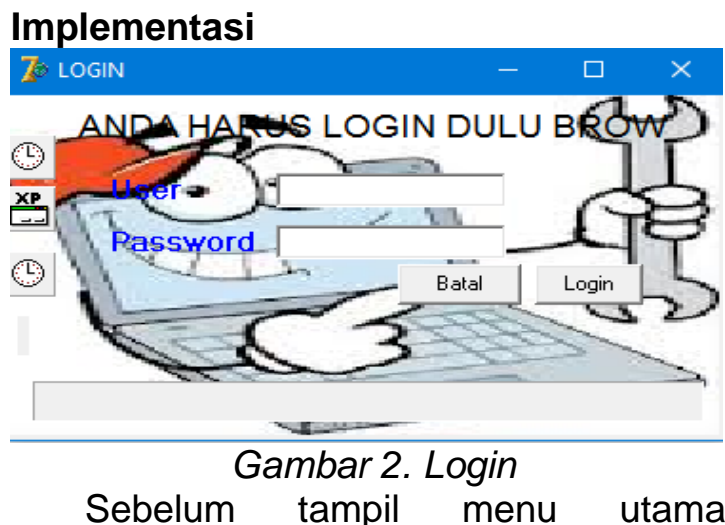
diharuskan untuk login. Hanya admin dan user yang sudah terdaftar di sistem yang dapat login untuk mengakses aplikasi.

\section{Tampilan Form Tampilan Utama}

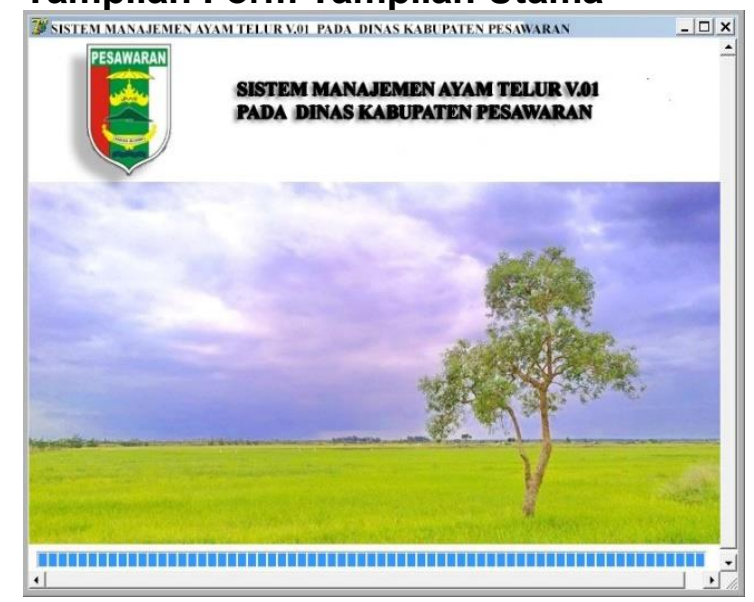

Gambar 3. Tampilan Utama

Form tampilan utama ditampilkan pertama kali saat user berhasil melakukan login.

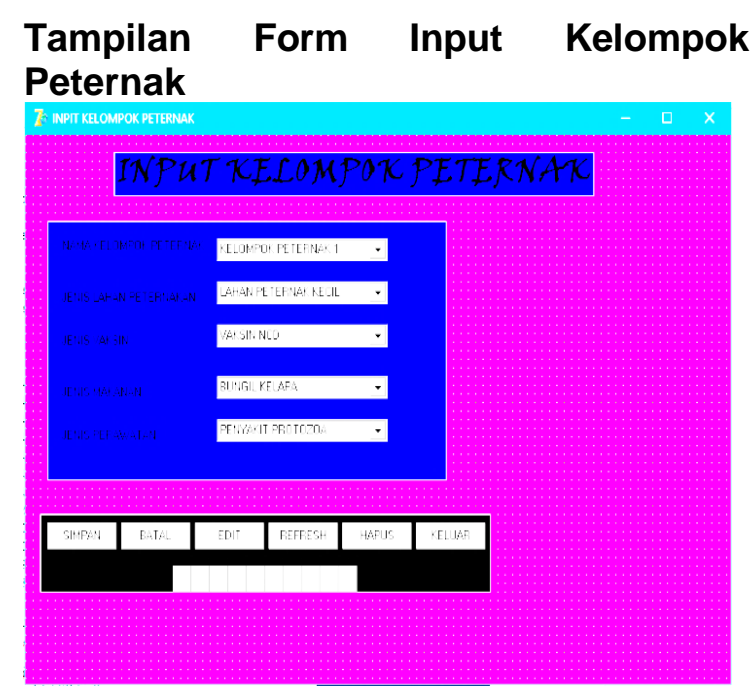

Gambar 4. Input Kelompok Ternak 
Form input kelompok peternak ini ada jika kita ingin menambahkan anggota baru didalam kelompok peternak klik sub tambah

\section{Tampilan Form Input Data Anggota Kelompok Peternak}

Form input data kelompok peternak ini ada jika kita memilih sub menu data dan ingin menambahkan anggota baru didalam kelompok peternakan .

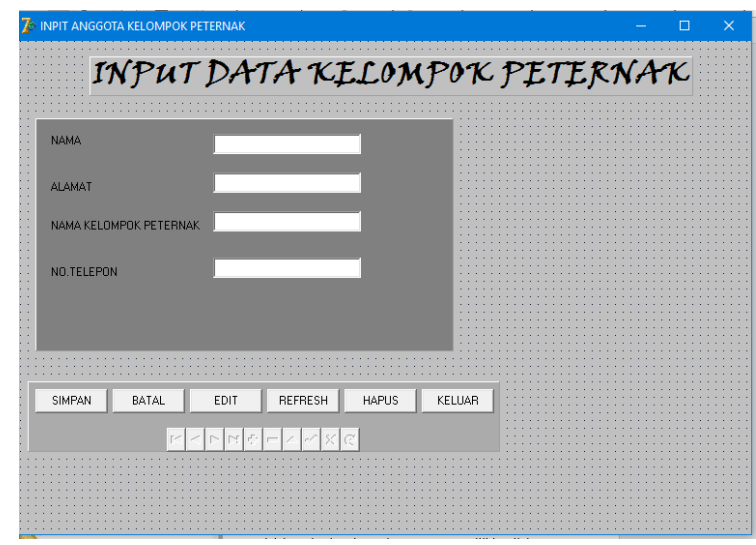

Gambar 5. Data Anggota Kelompok
Peternak

\section{SIMPULAN DAN SARAN}

Dengan dibangun sebuah sistem pendukung keputusan Menentukan Kelayakan Penerimaan Bantuan Pengusaha Ayam Petelur Oleh Dinas Peternakan Kabupaten Pesawaran Menggunakan Metode Fauzy Saw yang dapat membantu pemberian modal usaha bagi pengusaha ayam. Perhitungan Metode SAW ini diterapkan berdasarkan kriteria-kriteria dan bobot yang telah ditentukan, dimana perhitungannya dengan melakukan normalisasi matrik semua kriteria. hasil akhir perangkingan diperoleh :V1 $=64,5, \mathrm{~V} 2=60, \mathrm{~V} 3=58,5$ , V4 $=51,5, \mathrm{~V} 5=69,5, \mathrm{~V} 6=61, \mathrm{~V} 7=46$ , dan $\mathrm{V} 8=58.5$. Nilai terkecil ada pada perengkingan $V 7$, dengan demikian alternative A7 (Budi) adalah alternative yang terpilih sebagai alternative terbaik. Oleh karena itu peternakan budi adalah peternakan yang berhak menerima bantuan modal usaha dari Dinas Kabupaten Pesawaran.
Jika ada, ucapan terimakasih ditujukan kepada institusi resmi atau perorangan sebagai penyandang dana atau telah memberikan kontribusi lain dalam penelitian. Ucapan terimakasih dilengkapi dengan nomor surat kontrak penelitian.

\section{DAFTAR PUSTAKA}

Adi Yuliato Sistem Pendukung Keputusan Pemberian Modal Usaha Ayam Petelur Pada Mulawarman Farm Di Desa Tegal Sari Menggunakan Metode Ahp.

Hanifa, Muhamad Muslihudin, Sri Hartati. 2016. Sistem Pendukung Keputusan Menentukan Besar Gaji Untuk Guru Honorer Di Kabupaten Pesawaran Menggunakan Metode Fuzzy SAW. Jurnal Teknologi. IST Akprind Yogyakarta. Vol. 9, No. 1 Hal. 83-88. IST Akprind. Yogyakarta.

Made Astradanta, I Made Agus Wirawan, I Ketut Resika Arthana Pengembangan Sistem Penunjang Keputusan Pemilihan Tempat Kuliner Dengan Menggunakan Metode AHP Dan SAW Vol.5, No.2, (2016)

Muslihudin, Muhamad. A. Wulan Arumita. 2016. Pembuatan Model Penilaian Proses Belajar Mengajar Perguruan Tinggi Menggunakan Fuzzy Simple Additive Weighting (Saw)(Sudi: Stmik Pringsewu). SEMNASTEKNOMEDIA. AMIKOM Yogyakarta. Vol 4, No 1. Hal 4.1131 - 4.11-36. STMIK AMIKOM. Yogyakarta.

Rina Wati, Evi Mayasari. 2015. System Pendukung Keputusan Pemilihan Bibit Sapi Unggul Dengan Metode Simple Additive Weighting (SAW) Pada Peternakan Sapi Sri Angung Padang Ratu Lampung Tengah Jurnal TAM. Vol.5, Hal.22-28. STMIK Pringsewu.

Supriyanto., Heru. 2013. Sistem Penunjang Keputusan Untuk Menentukan Ayam Broiler Berkualitas Baik Berbasis Web. Jurnal TAM.Vol.2, No.2, STMIK Pringsewu.

\section{UCAPAN TERIMAKASIH}


Widi Ayu Pangestu. 2016. Sistem Pendukung Keputusan Menentukan Tataletak Perkantoran Polres Pada Kabupaten Pesawaran Dengan Metode Simple Additive Weighting Jurnal TAM. Vol.6. N0.1. STMIK Pringsewu.

Wulandari, Ahmad Mustofa, Ponidi, Muhamad Muslihudin, Firza Adi Firdiansah. 2016. Decision Support System Pemetaan Lahan Pertanian Yang Berkualitas Untuk Meningkatkan Hasil Produksi Padi Menggunakan Metode Simple Additive Weighting (SAW). SEMNASTEKNOMEDIA. AMIKOM Yogyakarta. Vol 4, No 1. Hal1.3-19 1.3-24. Februari 2016

Kusumadewi, Sri., Hartati, S., Harjoko, A., dan Wardoyo, R. 2007. Fuzzy MultiAttribute Decision Making (FUZZY MADM). Yogyakarta: Penerbit Graha IImu. 